\title{
Detection of Photoacoustic Transients Originating from Microstructures in Optically Diffuse Media such as Biological Tissue
}

\author{
Christoph G. A. Hoclen, Andró Dekker, and Frits F. M. de Mul
}

\begin{abstract}
The generation and detection of broadband photoacoustic (PA) transients may be used for on-axis monitoring or for imaging of optically different structures in the interior of diffuse bodies such as biological tissue. Various piezoelectric sensors are characterized and compared in terms of sensitivity, depth response, and directivity with respect to spherical broadband acoustic pulses. The influence on the sensor output of acoustic interference and rofraction of the PA transients at the sample-sensor interface is discussed. Ring detectors are suitable for deep on-axis detection thanks to their strong directional sensitivity, and small disk sensors are most suited for 3-D imaging of microstructures such as the (micro) vascular system. Voltage and charge preamplification schemes are compared in terms of the signal-to-noise ratio (SNR). In all cases, the preamplifior noise turns out to be the limiting factor for the sensitivity. Based on experimental data, for sevoral sensor types and optical wavelengths, the theoretical detectability of PA signals generated by blood-like absorbers in biological tissuo is discussed.
\end{abstract}

\section{INTRODUCTION}

$\mathrm{P}$ HOTOACOUSTIC (PA) signal generation [1]-[7] may be used to detcrmine tissue characteristics [8] [15] or to construct tomographic images of biological tissues [16][18]. The technique is based on the generation of a pressure pulse by an optical absorber following pulsed irradiation. The PA pulses may have a bandwidth up to more than $50 \mathrm{MH}_{z}$ [7]; [19] [21]. Detection of this acoustic response allows the possibility of mapping optical characteristics of the interior of the sample. For modical applications, the imaging of the (micro) vascular system, tissue depth profiling, or PA spectroscopy in a well-defined volume would be of utmost interest.

In principle, a wide variety of techniques is available for the detection of acoustic transients, based on the detection of the displacement, the velocity, or the density of particles in the medium. Here, only the most important techniques are briefly discussed. Piczoclectric detection turns out to be a very suitable technique for the detection of PA signals in tissue as with ultrasound pulse ccho imaging. An important difference, however, is that the piczoclectric elements in the pulse echo technique are used for transmission and detection of the acoustic; pulses, and, in PA imaging,

Manuscript received May 12, 1999; accepted April 25, 2000.

The authors are with Univorsity of Twonto, Departmont of Appliod I'hysics, 7500 AE Enschede, The Nethorlands (c-mail: mul@otn.utwente.nl). they are only used for detection. Characteristics of piczoclectric detection will be discussed, and some transducers that have been constructed and used for PA detection and imaging are characterized. We will focus on detection of PA signals with the purpose of depth profiling and 3-D imaging of microstructures in tissuc. 'This requires reconstruction of the acoustic wave fronts and, thus, the use of small sensing areas. It turned out that for the purpose of PA measuromonts in tissue, commorcially availablo detectors were not sensitive enough. This was mainly due to an insufficiont tuning of the preamplification characteristics to the required frequency bandwidth of the PA signals. For these reasons, we decided to undertake a thorough investigation into the signal processing characteristics of PA detection. Signal-to-noise ratios (SNR) had to be reconsidercd. As a result, we were forced to dosign our own line of probes. The rosult of this investigation is presented subsequently. As a general conclusion, we state that, provided proper care has been taken of PA signal processing and a proper mix of requirements of resolution, dimensions, depth, preamplification, and noisc can be obtained. PA array detection for 3-I) imaging of structures in tissue is very feasible.

\section{Detection of Piloroacoustic Ultrasound}

Common techniques for the detection of acoustic waves at the surface of a sample are based on piczoelectric, capacitative, electromagnetic, or laser interferometric principles [22]. For PA imaging of tissue structures, we need broadband sensors ( $>50 \mathrm{MH} /$ ) signals with amplitudes in the kiloPascal range (corresponding with displacements in the picometer range) [7], [19]. To obtain a high latcral resolution, the sensors should approximate point detection (spot diameter $<100 \mu \mathrm{m}$ ) at the tissuo surface.

Laser interferometers or piozoelectrics are the most suitable sensors for PA tissue sensing. Interferometers as well as piezoclectric sensors can be built to have a flat response less than 1 up to $100 \mathrm{MHz}$ [23], [24]. Broadband piczoclectric transducers may be up to about $30 \mathrm{~dB}$ more sonsitive than laser interferometers covering a comparable bandwidth (c.g., $10 \mathrm{MHz}$ ) [22], [25]. For rough and optically poor reflocting surfaces such as tissue, the difference will even be significantly largor. A piczoclectric point-contact detection threshold of about $0.2 \mathrm{pm}$ with a detection bandwidth of 10 MIIz has been reported [23], which should be 
compared with the detection threshold for interferomet; ric detection [22] of several picometers. From a sensitivity point of view, piezoclectric detection scoms to be favorable, but, for the best lateral resolution, the laser interforometor is the best option thanks tio its point-contact character. The higher sensitivity and ease of construction and operation of piezoelectric sensors make these the best choice for our purpose, although interesting results using interferometric detection of ultrasound have been reported recently [26]. Measurements with several prototypes of a PA probe intended for medical imaging and based on piezoclectric detection have becn reported [8], [14], [18].

The piczoelectric effect is described by a combination of the electrical relationship $D=\epsilon E$ and the mechanical rclation $S=s T$ of the matcrial, whore $D$ is dielectric displacement, $\epsilon$ is permittivity, $E$ is electric ficld strength, $S$ is strain, $s$ is compliance (stiffness coefficiont), and $T$ is applied stress. The equations can bo combined in many ways to obtain a set of piezoelectric constitutive relations [27]. For ultrasound detection, ofton the piczoelectric voltage constant $g$ and charge constant $d$ are used with the relations:

$$
D=\varepsilon E+d T \quad \text { or } \quad E=D / \varepsilon-g T
$$

where $d=\epsilon g$. The coefficients $g, d, \epsilon$ and $s$ are tensors and are generally characterized by two subscripts to indicate the components of the tensors.

An important group of piczoelectric materials are tho piezoelcctric ceramics, c.g., the sintered forroelectric ceramic load zirconium titanium oxides (PZT), consisting of small ferroclectric domains. Another important class of piezoelectric matcrials are those that can be deposited as a thin film on a substrate, e.g., zinc oxide ( $\mathrm{ZnO}$ ). Also, ferroelectric polymer films have been developed, c.g., polyvinylidene difluoride $\left(\mathrm{PVF}_{2}\right)$. Generally, piezoclectric polymer films are regarded as the materials preferred for hydrophones (detectors of acoustic waves in liquids) because of their large $g$ constant. Ceramics generally have a high piczoelectric stress constant and would be proforable for ultrasonic generation. Quartiz has a high quality factor and is used for frequency stabilizers for example. $\mathrm{PVF}_{2}$ [28] is attractive for medical imaging because its acoustic impedance closely matches the impedance of tissue, and it is mechanically flexible and bottor resistant to mochanical shock than ceramics [29]. Spot-poled membrane polymer hydrophones are highly desirable as detectors in pulsed ultrasound measurement studics because of their broadband non-perturbing properties [30] and have been presented as suitable sensors for ultrasonic dosirnetry [31]. Polymer hydrophones with a diameter as small as $0.1 \mathrm{~mm}$ have becn made [32]. Studies on the directional. response of miniature hydrophones revealed large difforences botween individual hydrophones (polymeric as well as coramic) and the moasured values could not be rolated satisfyingly to scveral theoretical models [33]. However, all of the models were based on diffraction theory, and acoustic reflection and refraction wore not taken into account.
A 9- $\mu \mathrm{m}$ thick $\mathrm{PVF}_{2}$ membrano hydrophone has becn reported for use in the 1- to $100-\mathrm{MHz}$ frequency range [24]. In this range, the response was concluded to be flat within ca. $5 \mathrm{~dB}$, which makes this film suitable for high resolution PA tissuc imaging. The coefficient $g$ was concluded not to depend on the frequency, but $d$ and $\varepsilon$ do vary (similarly) with frequency. This would make voltage detection more suitable than charge detection for broadband signals, as long as the output does not depend on the sensor capacitance. If the latter is not fulfilled, this may result in loss of sensitivity with increasing frequency [34]. However, cxperimental data in the range from 0.5 to $100 \mathrm{MHz}$ showed a smooth and flat, frequency response within $3 \mathrm{~dB}$ [35]. Ofton $\mathrm{PVF}_{2}$ sensors are used with a voltage amplificr. Signal amplification schemes have been discussed [36], but no goneral conclusions could be drawn. For a 0.5-mim diameter $\mathrm{PVF}_{2}$ needle hydrophone (thicknoss, $9 \mu \mathrm{m}$ ), a sensitivity of $30 \mathrm{nV} / \mathrm{Pa}$ has been reported [37]. However, to find the detection limit, not only the sensitivity, but also the noise level or the noise equivalent pressure $P_{c n}$, is needed. Often, the $P_{e n}$ in a 1-Hz band is used as (a measure for) the minimum detectable pressure. It is related to the scnsitivity $\eta(\mathrm{V} / \mu \mathrm{Pa})$, the measured noise voltage $E_{n}(\mathrm{~V})$, and the measurement bandwidth $\Delta f(\mathrm{~Hz})$ according to the relation $[30]$ :

$$
20 \log \left(P_{c n}\right)=20 \log \left(\frac{E_{n}}{\eta \sqrt{\Delta f}}\right) \quad[d B \text { re } 1 \mu P a] .
$$

The measurcment bandwidth was $300 \mathrm{kPa}$, so the total noise equivalent pressure was $550 \mathrm{~Pa}$. We have obtained much smaller $P_{\text {cn }}$ values, but with a comparable total noise equivalont pressure, for a measurement bandwidth of about $65 \mathrm{MHz}$. Because the spectral noise distribution often is far from white, this is not a reliable way to predict the minimum detcctable prossure for other measurement bandwidths. Not only the SNR and the absolute scnsitivity are of importance, but, also a good pulse response. This is much more easily obtained with polymers than with ceramics.

\section{Pifzomlectrle Tinn-Disk Detection or BROADBAND PA SIGNALS}

PA imaging requires small sensors to achieve a high rosolution. The thickness has to be small enough to have an acoustic transit time that is smaller than the duration of the signal. The diameter has to be small enongh to avoid destructive aconstic interforence across the surface of the detector. A sensor may bo characterized by its depth rosponse and its directivity for a standard broadband signal. Depth response expresses the dopendence of the sonsor output amplitude on the on-axis detection distance. The dircctivity expresses the dependence of the sensor signal amplitude on the angle of incidence and, thus, on the relative translation of the source perpendicular to the scnsor axis. The depth of the source is a parameter for the directivity. $\Lambda$ measure for the directivity is the half width at 
hall maximum (HWHM) of the sensor output amplitude as a function of translation.

For a thin-disk piezoclectric sensor for which only the thickness mode is relcvant (neglecting 1,3- and 2,3coupling, whore 1 and 2 are the transverse directions and 3 is the axial direction) and with a thickness much smaller than the characteristic wavelength of the acoustic signal, the response is determined by the normal component of the transmitted signal. The time-dependent piezo voltago $V_{p}(t)$ and surface chargo $Q_{p}(t)$ can bo obtained by averaging the normal componont of the transmititied pressure over the detector surface:

$$
\begin{gathered}
V_{p}(t)=\frac{g_{33} t_{p}}{\Lambda} \int P(\mathbf{r}, t) T_{A}(\mathbf{r}) \cos \theta_{2}(\mathbf{r}) d A \\
Q_{p}(t)=d_{33} \int P(\mathbf{r}, t) T_{A}(\mathbf{r}) \cos \theta_{2}(\mathbf{r}) d A
\end{gathered}
$$

where $t_{p}(\mathrm{~m})$ is the thicknoss of the disk; $A\left(\mathrm{ml}^{2}\right)$ is the sertsor surface area; $P(\mathrm{~Pa})$ is the pressine and $T_{A}$ is the amplitude transmission, both at the sensor surface; and $\theta_{2}$ is the angle of the refracted wave in the sensor. $g_{33}$ and $d_{33}$ aro the thickness mode piczoclectric constants. If coupling betwoen the radial and thickness modes is takon into account, the response is reduced because the 3,1- and 3,2-coupling coefficionts have inverse polarity compared with the 3,3coupling. Because, in most, cases, the lateral dimensions of the sensor arc much larger than the wavelength of the acoustic signal, this contribution is expected to be small.

The voltage incrcases with the scnsor thickness as long as the sensor is thin compared with the wavelength of the signal in the sensor. According to the supcrposition principle, every PA response can be regardod as a composition of point-source responses. A small spherical source generates a bipolar signal that is characterized by the poak-peak duration $\tau_{p p}$. The maximum sensor thickness is approximated by

$$
t_{\max }=\frac{1}{2} \nu d \tau_{p p}
$$

where $\nu_{d}$ is the acoustic phase volocity in the piezoelectric medium along the poling axis, and it is assumed that significant reflection at the backing material may occur. With this thickness, a bipolar PA pulse will broaden somewhat during the detection, but $\tau_{p p}$ of the sensor signal is the same as for the $P \Lambda$ pulse itsolf. If the backing material is acoustically matched, the thickness can be two times larger.

Expression (3) for the sensor signal shows that, the output amplitude will be related to the angle of incidence, the sensor diameter, and spatial length of the acoustic transicnt $P(\mathbf{r}, t)$. Upon increasing the angle of incidence, tho average pressure on the sensor is reduced, and, thus, the sensor shows enhanced forward sensitivity. But also, for on-axis detection, the interference can be significant and may influence the deptlı response. For point detection (i.e., for vanishing capacitance), the total charge vanishes, but the voltage is at a maximum; for large sensors caused by interference, the total charge is at a maximum, but the signals will be severely distortod, and the voltage will drop. $\Lambda$ compromise has to be found. This will be illustrated subsequently. To maximize the average surface charge, the phase difference betwon the signals arriving at the center and at the edge of the sonsor should be smaller than $\tau_{p p} / 2$. For on-axis detection, this defines the maximum sensor radius $R_{\text {nax }}$ for maximum charge genoration with limited signal distortion:

$$
R_{\max }=\sqrt{\nu \tau_{p p} z}
$$

where $\nu(\mathrm{m} / \mathrm{s})$ is the acoustic phase velocity in the samplo and $z$ is the depth at which the source on-axis is located. The minimum depth for a source to be detected without signal loss determines the maximum sensor radius. As an cxample, for the optimal detection of a spherical $\mathrm{P} \Lambda$ source cmitting a signal with $\tau_{p p}=20 \mathrm{rss}$ located at $1 \mathrm{~mm}$ depth in water, $R_{\max }=170 \mu \mathrm{m}$.

To be able to choose a proper detector diameter, we performed a scries of simulations of the on-axis detection, considering acoustic interference. The Gaussian spherical source model [6], [7] was used with $\tau_{p p}=20 \mathrm{~ns}$. The maximum signal amplitude and the least distortion of the piezo voltage $V_{p}$ is obtained for the smallest sensors. This has, however, the disadvantage that, at the same time, the surfacc charge $Q_{p}$ is reduced and will vanish for point detection. Assuming short acoustic pulsos $\left(\nu \tau_{p p} \ll R\right)$ for dotection distances smaller than the sonsor diamotor, $V_{p}$ and $Q_{p}$ become independent of depth. With increasing sensor diameter, $Q_{p}$ reaches a maximnm, but $V_{p}$ will furthor decrease because it is proportional to the average pressure. Without much signal distorlion, the maximum surface charge and the maximum piezoclectric voltage are obtained with a detector radius of $0.1 \mathrm{~mm}$ for a detection distance of $1 \mathrm{~mm}$. This corresponds very woll with the value of $122 \mu \mathrm{m}$ calculated with (5) and shows the applicability of this relationship.

However, this optimization is not the only criterion for PA detection because, for PA imaging, the sensors should be as small as possible to obtain maximum resolution. 'I'his conflicts with maximum charge generation, and a compromise has to be found.

\section{Capacitivli, Signat, J_oss}

Because of the small sizes of the piczoclectric element, its capacitance $C_{p}$ may bo very small. The signal amplitiude $V_{p}$ is reduced because of the load capacitance, which consists of the stray capacitances $C_{s}$ and the input capacitance $C_{i}$ of the opcrational amplifier [Fig. 1(a)]. For voltage detection, this rosults in an effective input voltage $V_{d}$ at the amplifier input. In case the piezoelectric material is coupled capacitively, this coupling capacitance $C_{c}$, which reduces the capacitance of the sensor, should bo taken into account, and the effective capacitance of the piezoelectric element should bo used, given by $C_{p} C_{c} /\left(C_{p}+C_{c}\right)$. This is important for sensors with a small $C_{p}$. The presence of 

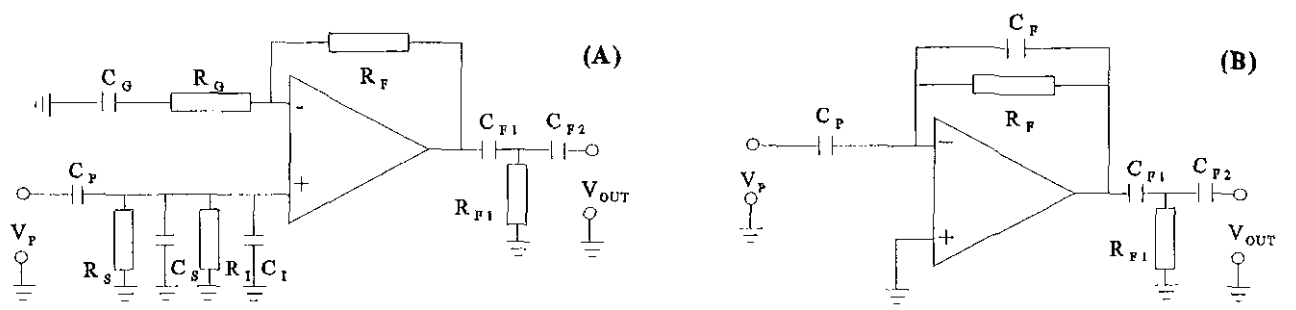

Fig. 1. Preamplifier configurations for piozoelectric detection of aconstic signals. A) Voltage umplification; B) charge amplification. Symbols: $V_{p}=$ piezo voltage caused by bound cherges; $C_{p}=$ capacitance of piezoelectric sensor; $C_{s}=$ stray capacitanco; $C_{i}=$ input capacitance of OpAmp; $C_{g}=$ capacitance to reduce DC-gain; $C_{f}=$ feedback capacitance; $C_{f 1:} C_{f 2}=$ filter capacitances; $R_{s}=$ shunt resistance; $R_{i}=$ input impedance of $\mathrm{OpAmp} ; R_{f}=$ gain resistance; $R_{f}=$ food back resistance; and $R_{f .1}=$ filter resistance.

$$
\begin{aligned}
& \left(\frac{V_{\text {out }}}{V_{p}}\right)_{C A}=-\frac{j \omega R_{f} C_{p}}{1+j \omega R_{f} C_{f}} \rightarrow-\frac{C_{p}}{C_{f}} \text { for } \omega \gg \omega_{0} ; \\
& \left(\frac{V_{\text {out }}}{V_{p}}\right)_{V A}=\frac{j \omega R_{t} C_{p}}{1+j \omega R_{t} C_{t}} \frac{1+j \omega\left(R_{f}+R_{g}\right) C_{g}}{1+j \omega R_{g} C_{g}} \rightarrow \frac{C_{p}}{C_{t}}\left(1+\frac{R_{f}}{R_{g}}\right) \text { for } \omega \gg \omega_{0}
\end{aligned}
$$

the other capacitances causes an attenuation of the signal amplitude (above the cut-off frequency) given by

$$
\frac{V_{d}}{V_{p}}=\frac{C_{p}}{C_{p}+C_{s}+C_{i}}
$$

For small sensor capacitances, this signal loss can be significant. As an example, a $0.2-\mathrm{mm}$ diameter $\mathrm{PVF}_{2}$ sensor $\left(\epsilon_{r}=12\right)$ with a thickness of $9 \mu \mathrm{m}$ is taken. The capacitance is $0.37 \mathrm{pF}$, and, with $C_{s}=C_{i}=2 \mathrm{pF}$, this results in an attentuation by a factor of 12 . In case of charge amplification (CA), there is not such a signal attenuation, but then the gain is limited by $C_{p}$ as is shown later.

For sevcral piezoelcctric materials $\left[\mathrm{PVF}_{2}, \mathrm{P}\left(\mathrm{VF}_{2}-\right.\right.$ TrFE), PZT-4, PXE-42] [27], [38]-[41], the sensitivity $\eta_{\mathrm{v}}$ of a disk sensor was calculated, assuming detection in an aqueous medium, according to

$$
\eta_{v}=g_{33} t_{\max } T_{1} R_{2} A_{C}
$$

where $T_{1}$ is the normal amplitudo transmission at the water-sensor interface, $R_{2}$ is the amplitude reflection at the sensor-backing interface, and $A_{C}=C_{p} / C_{t}$ is the capacitive voltage attonuation with $C_{t}=C_{p}+C_{s}+C_{i}$. Stainless stcel is taken as the backing material, but other materials that acoustically match to the sensor can be taken as woll. The sensor thickness is optimized according to (4). A stray capacitance of $2 \mathrm{pF}$ and a preamplifier input capacitance of $1 \mathrm{pF}$ was assumed. For 0.1 to $0.5-\mathrm{mm}$ diameter transducers, $\eta_{\mathrm{v}}$ varies between 0.2 and $3 \mu \mathrm{V} / \mathrm{Pa}$ for $\mathrm{PVF}_{2}$ and varies betwcen 0.6 and $1.4 \mu \mathrm{V} / \mathrm{Pa}$ for PZT.

The charge generation is proportional to the capacitance of the scnsors, i.e., proportional to the surface area. Charge generation in the ceramics is much larger than for quartz or $\mathrm{PVF}_{2}$. Because the diclectric constant of the coramics is much larger, the piezoclectric voltage is strongly reduced. The polymers show the largest intrinsic voltage sensitivity as given by $g_{33}[$ soe (1) and (3)].
For the large sensor diametcrs, the effective output voltage of the polymor films is highor than that for the other piczos, but, for the smaller diameters, the capacitive loss is increasingly important, and the ceramics show better performance. With respect to the charge generation, the ceramics are superior.

Piezoclectric ccramics have also some drawbacks. Because of the large impedance mismatch with water, they tend to ring. This can be avoided if the backing is aconstically matched. At the sample-transduccr interfacc, a large part of the signal is reflected back into the sample. This may be complicating if it leads to significant reflections in the simple that are also detected. Use of acoustically matching laycrs may reduce this problem, but the construction of the laycrs for broadband transducers is difficult to accomplish. For piezoclectric polymers, the roflections can be suppressed casily by matching. Another advantage of the polymers is the small thickness of the sensors, which makes them loss sensitive for radial forces. As a result, the transducer can be regarded as a thin disk operating in thickness mode, in contrast to ccramic sensors with optimized dimensions for which the thickness approximates the lateral dimensions.

\section{Signal Prenmpitifichtion}

In principle, two preamplification schemes are possible: voltage amplification (VA) and CA. Signal preamplification for small hydrophone elements is not discusscd much in literature. Sometimes facts are mentioned that are only rolevant for voltage amplification (e.g., [35]). Often VA is assumed or presented as the only possibility [36]. In other cases, some advantages and disadvantages of both amplification schemes arc mentioned but without thorough discussion of small signal detection or a comparison of SNR 
[42]. CA has the advantage that the output is independent of the cable capacitance and stray capacitances, but the disadvantage that the noise level is directly proportional to the load (wiring) capacitance. A disadvantage of $V \Lambda$ is the voltage coupling loss that results from a small sensor capacitance relative to the load capacitance. In a comparison of the two types of preamplifiors [42], it, was demonstratied that a high sonsitivity and flat frequency response can be achicved by using $\mathrm{CA}$, but, in fact, there was little difference in the minimum detectable pressure level for the two amplifiers with short; wiring.

The electrical circuits for VA and $\mathrm{CA}$ are shown in Fig. 1. Apart from the filters at the output of the operational amplificrs that are used to reduce the noise at low frequencies (bolow $1 \mathrm{MH} /$ ), the transfor functions are given by (8) and (9) (see top of provious page)

where $C_{t}=C_{p}+C_{s}+C_{i}, R_{t}=R_{s} R_{i} /\left(R_{s}+R_{i}\right)$, the high pass cut off frequency $\omega_{0}=1 / R_{f} C_{f}$ for CA, and $\omega_{0}$ is the maximum of $1 / R_{f} C_{f}$ and $1 / R_{g} C_{g}$ for VA. The capacitance $C_{g}$ is used to reduce the offset at the output of the Op $\Lambda m p$, which results from the bias current at the non-inverting input. We see that, with $\mathrm{C} \Lambda$, the signal amplification is given by $G_{C A}=C_{p} / C_{f}$, i.e., the ratio of the piezo capacitance and the fecdback capacitance. For very small sensor capacitances $(<1 \mathrm{pF})$, it is not possible to amplify the signal because there will always be a feedback stray capacitance of about this valuc. With VA, the signal is amplified with the amplifier gain $G_{V A}=\left(R_{g}+R_{f}\right) / R_{g}$ but also attemuated by the capacitive quoticnt $C_{p} / C_{t}$. For the rolevant signal froquencios, the rolative signal amplitudes with the two amplification schemes are given by

$$
\frac{S_{V A}}{S_{C A}}=\frac{C_{f}}{C_{p}+C_{s}+C_{i}} G_{V A} .
$$

This shows that the voltage amplifier gives a higher rosponse than the charge armplifice if $G_{V A}>\left(C_{p}+C_{s}+\right.$ $\left.C_{i}\right) / C_{f} . \Lambda \mathrm{s}$ long as the output signal amplitude is not too small to make further amplification necossary, it is the SNR of the preamplifier that determines the detection linit.

The major noise sources in VA are the thermal resistance noise current $I_{n, R}$ from $R_{l}$, the noise current $I_{n,+}$ at the non-inverting input, and the noise voltage $U_{n}$ of the OpAmp [43]. Nlthough the detection circuit before the input of the OpAmp is a high pass filtor for PA signals, it is a low pass filter for the noise gencrated by $I_{n,+}$ and $I_{n, k}$. $\Lambda$ high pass filter at the output of the OpAmp effectively reduces this noisc. It is taken as a second-order filter with time constant $R C$. Using (9), the amplitude SNR is

$$
S N R_{V A}=\frac{\left(\frac{C_{p}}{C_{p}+C_{s}+C_{i}}\right) V_{p}}{\left\langle V_{n}\right\rangle_{V A}} .
$$

The nominator is equal to $\eta_{v}$. For $C_{p} \ll\left(C_{s}+C_{i}\right)$, the signal is proportional to $C_{p}$, and $\left\langle V_{n}\right\rangle$ decreases with increasing $C_{p}$. In this case, the best SNR is obtained with a ceramic sensor. The choice of $R_{t}$ for a given $C_{t}$ is not obvious and depends on the relative noise contributions. The

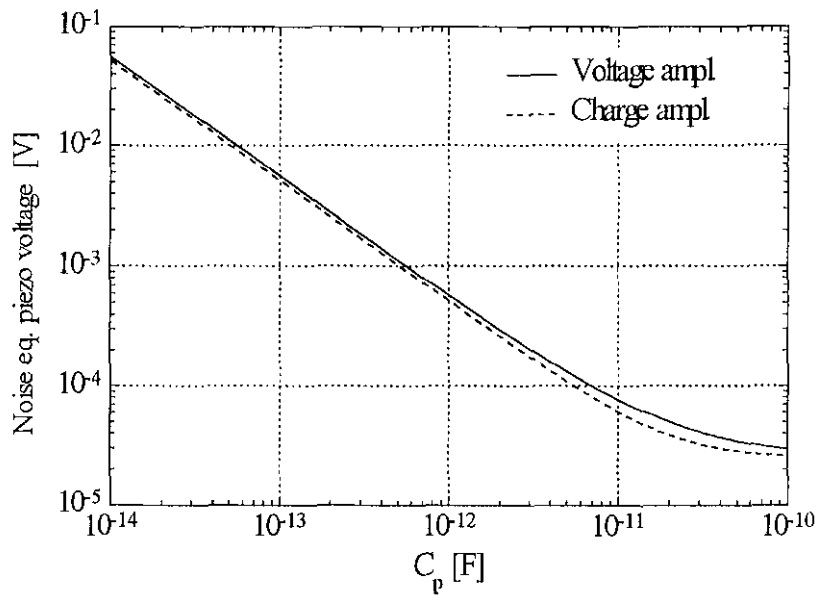

Fig. 2. The noise equivalent piezo voltage as a function of the piezo capacitance for voltage and charge amplification. 'L'he following parameter values were used: $C_{i}=2 \mathrm{pF}, C_{s}=2 \mathrm{pF}, C_{f}=1.4 \mathrm{pF}$, $f_{0}=1 \mathrm{MH} /, U_{n}=1 \mathrm{nV} / \sqrt{\mathrm{H}} /$, and $I_{n,-}=I_{n,+}=1.6 \mathrm{p} \Lambda / \sqrt{\mathrm{H}_{z}}$. The integral is taken from 0 to $100 \mathrm{MHz}$.

contribution to the final detector noise of $I_{n,+}$ is minimized by minimizing $R_{t}$; the contribution from the thermal noise is minimizod by maximizing $R_{t}$ (i.e., shifting the thermal noise to the lower frequencies). The lower limit of $R_{t}$ is determined by the $R C$-time needed for detection of the PA signals (ca. $1 \mathrm{MHz}$ ).

'The major noisc sources of the charge amplifier are the thermal noise from $R_{f}$, the noise cur'ent $I_{n,--}$, at the inverting input, and the noise voltage $U_{n}$ of the OpAmp [43]. Of the three noise sources, only $U_{n}$ is amplified. Using (8), the SNR is

$$
S N R_{C A}=\frac{\left(C_{p} / C_{f}\right) V_{p}}{\left\langle V_{n}\right\rangle_{C A}}
$$

With increasing $C_{p}$, the SNR increases until, at a large amplifier gain $\left(C_{p} \gg C_{f}\right)$, the output noise is dominated by $U_{n}$ and also becomes proportional to $G_{C A}=C_{p} / C_{f}$. For $\mathrm{CA}$ too, it is advantageous to use a coramic as sensor material.

A useful quantity is the noiso equivalent piczo voltage, i.c., the piozoelectric voltage that genorates a signal at the output of the detector with $\mathrm{SNR}=1$. This quantity is found using (11) or (12). A numerical cvaluation of the noise equivalent piozoelectric voltage $V_{p}$ is shown in Fig. 2 for both amplification schemes as a function of $C_{p}$. It was assumed that all of the time constants were equal to $1 /\left(2 \pi \times 10^{6}\right)$ s, corresponding to a frequency $f_{0}$ of $1 \mathrm{MH} \%$. For low noise OpArnps with a sufficiently large bandwidth, the following parameter values are realistic: $U_{n} \approx 1$ to $3 \mathrm{nV} / \sqrt{ } \mathrm{Hz}, I_{n,+} \approx 0.5$ to $2 \mathrm{pA} / \sqrt{ } \mathrm{Hz}$, and $I_{n,-} \approx 1$ to $15 \times I_{n,+}$. The parameter values were choson in these regions.

The figure shows that for very small sensor capacitances, the noise cquivalent voltage (or the SNR) is nearly the same for the two amplification schemes. The performance of the charge amplifier is somewhat betiter. For the 
TABLE I

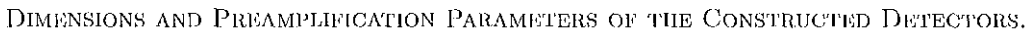

\begin{tabular}{|c|c|c|c|c|c|c|c|c|}
\hline Туре & $\begin{array}{l}\text { I.D. } \\
(\mathrm{mm})\end{array}$ & $\begin{array}{l}\text { O.D. } \\
(\mathrm{mm})\end{array}$ & Ampl. & $\begin{array}{l}C_{p} \\
(\mathrm{pF})\end{array}$ & $\begin{array}{l}C_{i}+C_{s} \\
(\mathrm{pF})\end{array}$ & $\begin{array}{l}C_{f} \\
(\mathrm{pH})\end{array}$ & $\begin{array}{l}V_{n} \text { rms } \\
(\mathrm{mV})\end{array}$ & $\begin{array}{l}\eta_{v} \\
(\mu \mathrm{V} / \mathrm{P} \mathrm{a})\end{array}$ \\
\hline Disk & & 0.2 & $\mathrm{VA}, G=10$ & 0.37 & $\overline{4}$ & & 0.98 & 2.0 \\
\hline Srrall ring & 0.37 & 0.67 & $\mathrm{VA}, G=10$ & 2.9 & 3.7 & & 0.33 & \\
\hline Large ring & 2.6 & 3.0 & $\mathrm{CA}, G=15$ & 20.8 & & 1.4 & 0.25 & \\
\hline
\end{tabular}

parameter values chosen, the maximum benefit of the CA is obtained for a sensor capacitance of ca. $30 \mathrm{pF}$. At this $C_{p}$ value, the signal to noiso amplitude ratio is ca. 1.5 times larger than that for VA. For larger capacitances, the benefit decreases again. So, in practice, there is hardly any difference between $\mathrm{CA}$ and VA with respect to the SNR. The preforable amplification scheme is determined by maximizing the signal amplitude as expressed by (10). For very small piezo capacitances, VA is preferred becauso of the higher signal, but, for larger piezo capacitances, $\mathrm{C} \Lambda$ is preferred because of the higher SNR. But what is important is that the limit of detection decreases approximatcly inversely proportional to $C_{p}$ for $C_{p}<10 \mathrm{pF}$. Although the piczo voltage generated by polymers is 5 to 20 times larger than for ceramics, the capacitance is 40 to 130 times smaller. For sensors with a diameter below about $1 \mathrm{~mm}$, coramies have a better SNR.

\section{Experimkntal, Piezoelletric Hydrophones}

Three hydrophones with different characteristics have been used for PA measurements. For the numerical calculations of the performance of the detectors, using the Maple package [44], well-known cxpressions for the signal transmission at the water-piczo interface [27], for the piczo voltage (3), and for the preamplification (8), (9) are uscd.

Because of the case of handling and the low acoustic impedance, the sensors were mado of $9-\mu \mathrm{m}$ thick biaxially stretched $\mathrm{PVF}_{2}$ film. For the imaging experiments, a diskhydrophone was used; for PA detection of sources at larger depths, two-ring detectors were constructed. For some experiments also, a 1-mm diametcr. $\mathrm{PVF}_{2}$ sensor was used with a film thicknoss of $28 \mu \mathrm{m}$.

For the disk and the small ring detector, a voltage amplificr was found to be somewhat more advantageous; for the large ring detector, a charge amplifier resulted in the best SNR. The diameter of the disk detector was a compromise between sensitivity, or SNR, and the requirement of point detection for optimal imaging resolution. The dimensions of the ring detectors were chosen to obtain two different depth ranges where the sensors have their optimum sensitivity combined with a narrow aperture. The main characteristics of these detectors are summarized in Table I.

The construction of the sensor, consisting of four disk detectors, is shown schomatically in Fig. 3. Four copper wires (diameter, $200 \mu \mathrm{m}$ ) arc embedded in Stycast in a

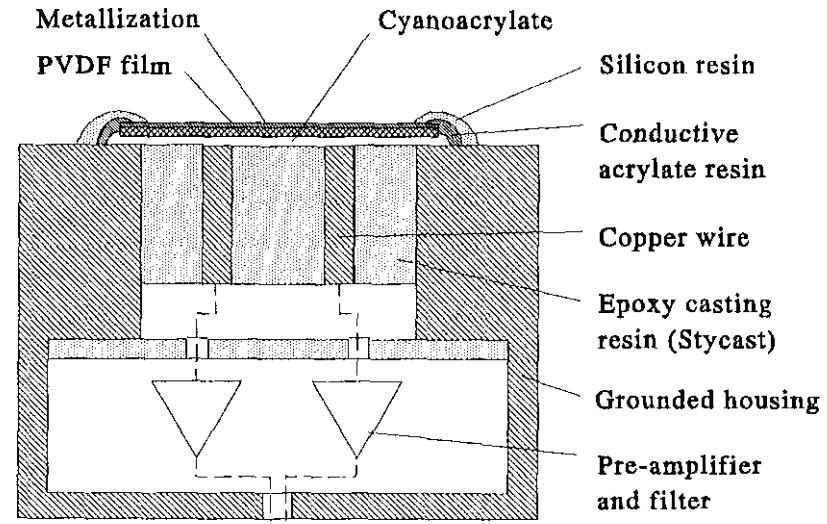

Fig. 3. Schematic drawing of the $\mathrm{PVF}_{2}$ disk detector. Coppor wires $(200 \mu \mathrm{m})$ arc emboddod in Stycast and are polished. The piezo film is glucd on top of this surface, and the copper wires act as signal elcctrodes that dotormite the diameter of the sensor. The preamplifiers aro mounted inside the housing.

grounded brass housing. The surface (perpendicular to the wires) is polished, and the piezofilm is glued on top of it, coupling the signal eloctrodes capacitively to the piczofilm. At the free surface, the film is motallized and connected to the brass housing by a conductive acrylate rosin. This connection is shiclded by a thin layer of silicon resin. The voltage preamplificrs, for which the low power video OpAmps AD810 and AD811 wore used, are mounted inside the dotector housing. The amplificr circuits act as a high pass filter to oliminate spectral noise contributions below ca. $1 \mathrm{MHz}$, at which point the spectral signal amplitudes are negligible. The bandwidth was always more than $65 \mathrm{MHz}$. For the charge amplificrs, as woll as for the voltage amplificx, the noise was concentrated at the lower frequencies in quite good agreement with theory. The total noise, however, was experimentally about a factor 1.5 larger than the theoretical values. The disk detector has a sensitivity of $2.0 \mu \mathrm{V} / \mathrm{Pa}$ as followed from cxtensive comparison with a calibrated necdle hydrophone (Precision Acoustics Ltd., UK) with an rms noise amplitude of abont $1 \mathrm{mV}$.

The ring detectors are constructed in the same way. $A$ stainless steel tube is embedded in Stycast cpoxy resin to replace the copper wires and to act as the signal electrode. Furthermore, after the attachment of the piero film, in the large ring detector, a hole was drilled in the center of the inctal tube, and a $600-\mu \mathrm{m}$ core diameter glass fiber was mounted in the sensor. The fiber facet was located just above the sensor surface. The hole was closed with 
silicon resin. For both ring detectors, tho Op $\Lambda$ mp CLC425 was used, which has somewhat bettcr characteristics than the AD vides OpAmps. The rms noise of the small ring detector was $0.33 \mathrm{mV}$ and, for the large ring detector, was $0.25 \mathrm{mV}$.

\section{VIT. T'RANSDUChir CinaraCthirizATION}

The performance of piezoelectric thin disk sensors very much depends on the reflection, refraction, and interfercnce across the interface with the sample. The PA signal generated by an extended source can be described as a simmation of the PA signals from smaller elements (superposition principle), so the signal from a small spherical source is used for the transducor characterization. Fig. 4 shows some experimental PA signals that were detected with the 200- $\mu \mathrm{m}$ diameter $\mathrm{PVF}_{2}$ transducer. The effective source geometries correspond with a homogencous sphere, a homogeneous cylinder, and a cylindrical shell. Intralipid dilutions and Evans Blue solutions were nsed to mimic tissue optical characteristics. Also, the PA signal generated by real tissuc containing artificial vessels with whole blood is shown. This is the kind of signal that is used for 3-D PA imaging of tissue samples. For the characterization of the transducers, wo 11se the depth response and the directivity of the sensors, defined as the amplitude maximum of the response for the detection of a bipolar aconstic pulse as generated by a spherical PA source [7]. The source is characterized by a $\tau_{p p}$ of 10 to $20 \mathrm{~ns}$. The depth responso is the signal maximum as a function of the depth of the source for on-axis detection. The directivity is the set of signal maxima plottod as a function of the lateral displacemont of the source with the depth as a parameter and is normalized with the signal at normal incidenee.

Measurements have boen performod to reveal the rolative depth responses of the various detectors. This is shown in Fig. 5. The experimental setup has been described in large detail elsewhere [18]-[21]. We used a Nd:YAG laser at $532 \mathrm{~nm}$ with 10-ns pulses of about $100 \mu \mathrm{J}$ cach. As the turbid medinum, we applied either a $10 \%$ Intralipid-10\% dilution or real chicken breast tissue. $\Lambda$ s the absorbor, we used either whole blood or an Fvans Blue solution with similar absorption. $\Lambda$ 10- $\mu \mathrm{m}$ diameter absorbing thread irradiated over a small length acted as the PA source. Theoretically, this signal has a $\tau_{p p}$ of 12 ns. Typically, a $\tau_{p p}$ betwoen 13 and 23 ns was measured, the broadening of which may be partially due to froquency-depondent absorption in water [7]. In the calculations, the theoretical value was used. Because the source strength was not woll reproducible, the experimental depth responses of the three detectors were normalized to correspond with the theoretical curves. The figure shows the relative large sensitivity of the ring detectors at a larger depth. For a depth $z>6 \mathrm{~mm}$, the large ring detector has the highest sonsitivity. $\Lambda t$ distances close to the surface $(z<1 \mathrm{~mm})$, the disk detectior has the highest scnsitivity, and, in between, the small ring detector is favorable. 'The significant deviations of the experimontal

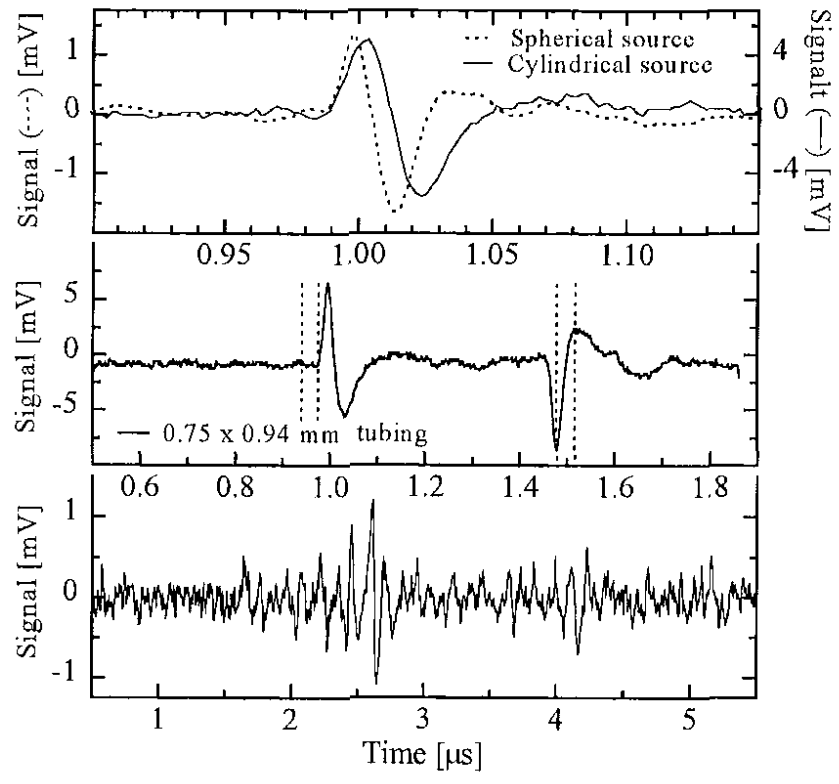

Fig. 4. Exporimontal PA sigrnals detected with a $200-/ \mathrm{m}$ diameter piezoelectric transducer. 'Ithe upper pand shows tho signals (averaged 64 times) genorated by spot illumination of a $10-\mu \mathrm{m}$ diameter absorbing strand in wator and by homogeneous illumination of this fiber in a $10 \%$ dilution of Intralipid $(10 \%)$. Detection distance is $1.5 \mathrm{~mm}$. The middlo panel shows the PA signal from an Evans J3he solution with $\mu_{f}=300 \mathrm{~cm}^{-1}$ flowing through a translucont nylon vessol (inner diameter, $750 \mathrm{\mu m}$; outer diameter, $940 \mu \mathrm{mm}$ ), which is located in a $10 \%$ dilution of Intralipid (10\%) and illuminated from aside with a glass fiber at a 1.5 -mm distanco. The clashed lines indicate the transit times from the nylon-water interfaces to the transducer. 'Tho pulse energy is $85 \mu \mathrm{J}$, and the signal is averaged 16 times. 'The lower panel displays the signal recorded just in front of a 6 -mm thick chicken broast sample that contains several $280-\mu \mathrm{m}$ inner diametor nylon capillarios (al; depths between 3 and $4 \mathrm{~mm}$ ) with flowing whole blood. The pulse energy is $300 \mu \mathrm{J}$; the signal is averaged 16 times.

sensitivitics at small depths from the theoretical curves are probably duc to the fact that the source actually is a short line source. For the ring detectors, a better preamplifier was used than with the risk detector. Using the same OpAmp for this detector will increase the performance by about a factor 1.5. The results cloarly show the advantage of the higher sensitivity of ring detectors for doep measurements.

The response of a detector dopends on the angle of incidence, the signal shape, the duration, the detection distance, and the diamcter(s) of the detector. Together, these paramoters determine the normally transmitted signal amplitude and the acoustic interference. lor the different detectors, the sensitivity for lateral translation of a PA source is quite different. These relationships have becn dotcrmined expcrimentally and theoretically (by numerical cvaluation). A $10 \mu \mu \mathrm{m}$ thick absorbing fibor illuminated over $70 \mu \mathrm{m}$ acted as the PA source, gencrating a bipolar PA signal with $\tau_{p p}=13 \mathrm{~ns}$. For the three detectors, the source was located at different depths: for the disk detector, at $1 \mathrm{~mm}$; for the small ring detector, at $3 \mathrm{~mm}$; and for the large ring, at $10 \mathrm{~mm}$. The result is shown in Fig. 6 . 


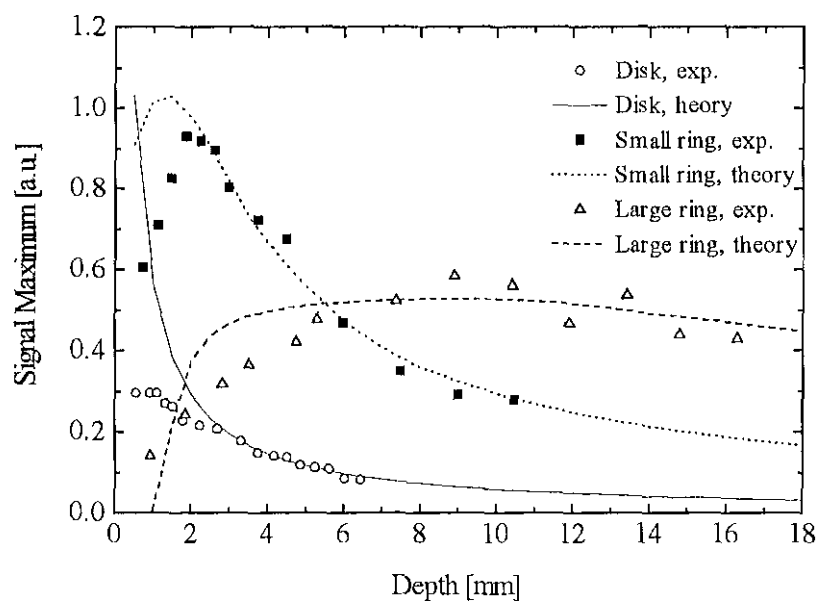

Fig. 5. Comparison of the depth response of a disk detector (O.D., $0.2 \mathrm{~mm})$, a small ring detector $(0.37 \mathrm{~mm} \times 0.67 \mathrm{~mm})$, and a largo ring detector $(2.6 \mathrm{~mm} \times 3 \mathrm{~mm})$ for a sphorical source. Calculations with $\tau_{p p}=1.2 \mathrm{~ns}$. The experimental data are normalized to fit to the calculated curves.

The figure shows that all of the detectors have about the same HWHM for the signal amplitude as a function of the relative translation (disk, $0.2 \mathrm{~mm}$ : HWHM $=0.2 \mathrm{~mm}$; small ring, $0.37 \times 0.67 \mathrm{~mm}$ : HWHM $=0.25 \mathrm{~mm}$; large ring, $2.6 \times 3 \mathrm{~mm}$ : HWHM $=0.2 \mathrm{~mm}$ ), but this is obtainod at very different depths. The figure shows that a larger ring has a (much) more pronounced forward sensitivity. Ring detectors, however, show side lobes in their directional sensitivity at a translation equal to the radius of the ring, and the signal shape is distorted. For line sources, this effect is even much more pronounced, and the side lobe can have a higher amplitude than the sensitivity for on-axis detection. If concentric rings are used for the dotection, this phenomenon can be reduced. This is shown in Fig. 7. The HWHM for the doublc ring detector is $60 \mu \mathrm{m}$ (for a source at a 5-mm depth), and, for the single ring detector, the HWHM is $76 \mu \mathrm{m}$. The directivity of the double ring detector is the result of the sum of the individual ring signals. Using time shifts may further incrcase the forward sensitivity. With multiple concentric rings, a very strong forward sensitivity can be obtained with a variable depth of focus. This may be used for decp on-axis monitoring of PA signals in tissue. Because of the large diameters, these detectors are not very suitable for integration in a 3-D imaging sensor, unless the detector is scannod across the skin surface.

\section{Detétetion Limits}

The relative capabilities of the three different hydrophones to detect a spherical PA source in an optically tissue-like medium as a function of the depth of the source is shown in Fig. 8. The source, with a diameter of $370 \mu \mathrm{m}$, has blood-like absorption. Experiments with a cylindrical source of this diameter in an Intralipid dilution with added

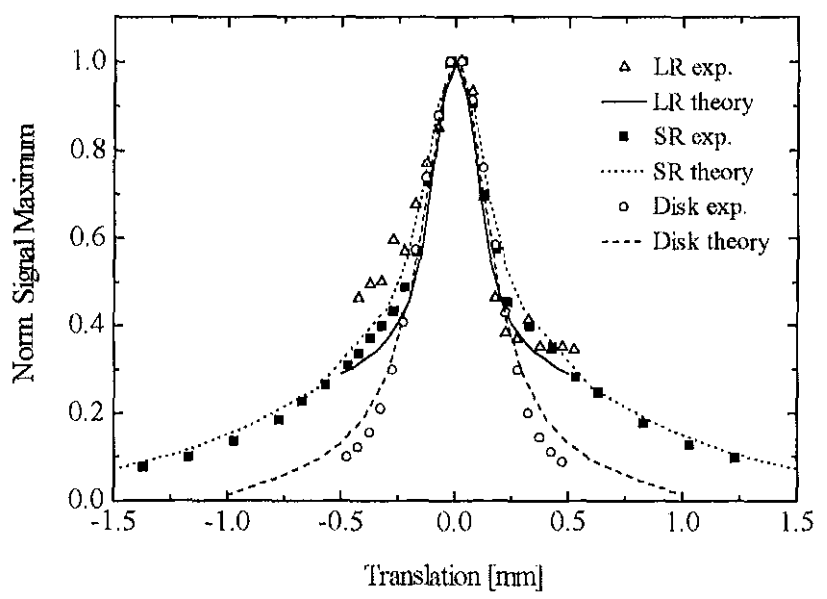

Fig. 6. Directional sensitivities of the large ring detection (LR), tho small ring detector (SR), and the disk detector. 'The normalized signal maximum is given as function of the translation of the point soince rolative to the detector. The source was located at $z=1 \mathrm{~mm}$ for the disk detector, $3 \mathrm{~mm}$ for the small ring dotector, and $10 \mathrm{~mm}$ for the large ring dotector.

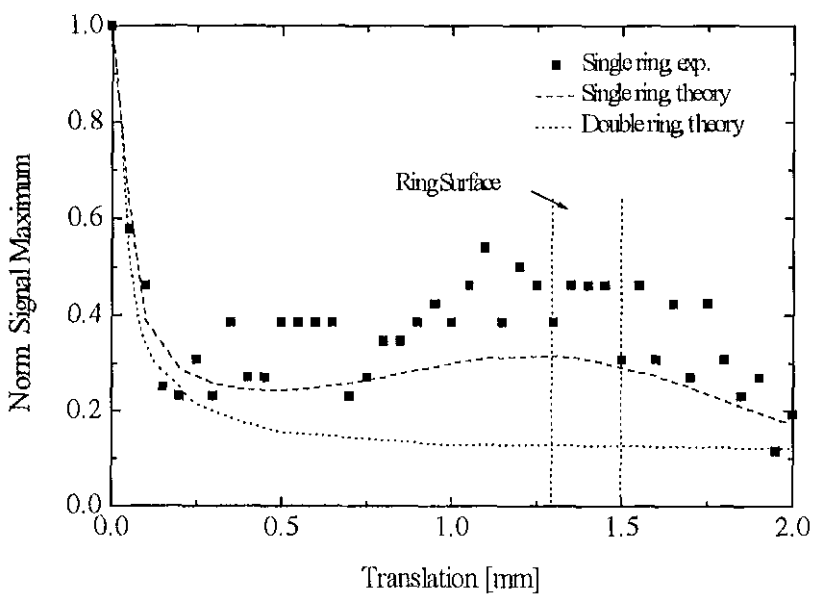

Fig. 7. Directional depondence of a single ring detector $(2.6 \mathrm{~mm} \times 3 \mathrm{~mm})$ and two concentric rings $(2 \mathrm{~mm} \times 2.1 \mathrm{~mm}$ and $3 \mathrm{~mm} \times 3.1 \mathrm{~mm}$ ) with a point sourco at a $5-\mathrm{mm}$ depth as a function of the relative translation. The experimental data are for the single ring detector. Calculations are for $\tau_{p p}=12 \mathrm{~ns}$.

absorber (Evans Blue) to obtain a reduced scattering coefficient $\mu_{s}^{\prime}$ of $0.75 \mathrm{~mm}^{-1}$ and an absorption coefficient $\mu_{a}$ of $0.1 \mathrm{~mm}^{-1}$ (corresponding to tissue) revcaled that, for a $180-\mu \mathrm{J}$ laser pulse at $532 \mathrm{~nm}$ with the large ring detector, the PA signal, averaged 128 timos, was detectable at a depth of $7.8 \mathrm{~mm}$ with a powor SNR of 10 . The rms noise was about $8.8 \mathrm{mV}$. For other optical parameter values, the diffusion approximation for an incident pencil beam is used to approximate the light fluence and to calculate the appropriate SNR values. For a spherical source with the same diameter as a cylindrical source, the PA signal is about, five times smaller. These data were used to determine the detcction limit for several configurations. The theorctical 


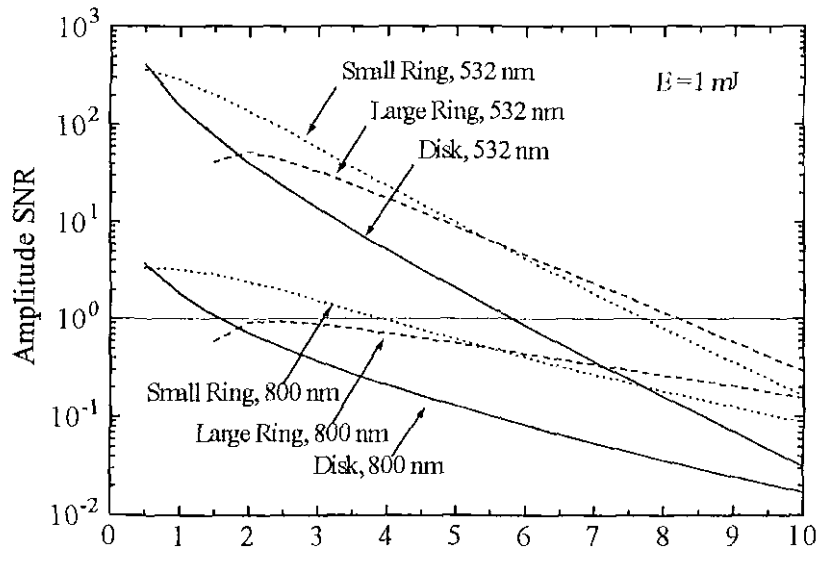

Fig. 8. Theoretical detectability of a PA signal from a $0.37-\mathrm{mm}$ dikmeter spherical source with blood-like ahsorption located in phantom tissue for three different detectors. Detection is in reflection mode. The calculations are for 1 -moJ laser pulse energy and for signals avoraged 128 times. The optical coefficicnts of the mediun are given in Table II.

depth responses of the three detectors wore used to find the rolative sensitivities. The noise of the amplifiers is assumed to be the same. The absorbed energy $E_{a}$ is proportional to $\mu_{a}$, so the signal at $800 \mathrm{~nm}\left(\mu_{a}=5 \mathrm{~cm}^{-1}\right)$ is about 60 times smaller than that at $532 \mathrm{~nm}\left(\mu_{a}=300 \mathrm{~cm}^{-1}\right)$ for equal laser pulse energies reaching the target. 'This offect will bo partly compensated by decreased scattering upon increasing wavelength. The optical parameters for bloodless tissue were taken as shown in Table II. The absorption is likcly to be about a factor 3 too large compared with in vivo measuremonts in tissue and should bo regarded as worst case.

Parameters that may be changed are the laser pulse energy $E, \mu_{n}$, and $\mu_{s}^{\prime}$ of the medium, and the detection limit. The latter dopends on the SNR characteristics of the detectors. Reducing the noise of a detector with a factor 2 or increasing the sensitivity of the sensor with a factor 2 (while kceping the noise constant) will shift the curve upward with the same factor. The same holds for an increase in light pulse encrgy. If the optical properties differ from the ones used hore, the curvos aro changed with a depth-rlependent factor that is defined by the change in the flucnce:

$$
\frac{\Phi}{\Phi_{0}}(z)=\frac{\mu_{t r}}{\mu_{t r, 0}} \frac{\operatorname{cxp}\left\{-\mu_{e f f}\left(z-1 / \mu_{t r}\right)\right\}}{\exp \left\{-\mu_{t f f, 0}\left(z-1 / \mu_{t r, 0}\right)\right\}}
$$

where the subscript 0 refers to the coefficients used here (scc Table II); $\mu_{t r}=\mu_{a}+\mu_{s}^{\prime}$ and $\mu_{e f f}=\left(3 \mu_{a} \mu_{t r}\right)^{1 / 2}$.

The figure shows that for detection distancos larger than $0.5 \mathrm{~mm}$, the small ring detector has higher sensitivity than the disk detector, and, for depths larger than 5 to $6 \mathrm{~mm}$, the large ring detector has the highest sensitivity, For the given assumptions with the disk detector, the spherical source can be detected with $532-\mathrm{nm}$ light up to a depth of $6 \mathrm{~mm}$. For the ring detectors, this is ca. $8 \mathrm{~mm}$. At larger depths, the ring detectors are increasingly favor- able, but, to detect the source, tho paramoter values have to be changed to get the curves above the detection limit. At $800 \mathrm{~nm}$, the detectors show the same relative bohavior, but the SNR of a measurcment does not docrease as fast with increasing depth as at $532 \mathrm{~nm}$. This is the rosult of the larger effoctive optical mean free path. In principle, it should be possible to increase the light onergy until the absorbed energy near the tissue surface is equal for the various wavclongths as long as there is no cavitation or plasma formation. Then, the curves for $532 \mathrm{~nm}$ and $800 \mathrm{~nm}$ start at the same value for small depth, and the source can bo detected up to abont $20 \mathrm{~mm}$ with the large ring detector (at $800 \mathrm{~nm}$ ) if the other parameters are kept constant. If, at $800 \mathrm{~nm}$, a 10 -m.J laser pulse is used (i.c., 10 times larger than at $5.32 \mathrm{rm}$ ), then, at a depth of $6 \mathrm{~mm}$, the SNR of the sensors are the same for both wavelengths, and, at larger depths, the noar infrared light is favorable.

For cylindrical sources, the PA signal decrease causod by the acoustic propagation is proportional to $r^{\sim 1 / 2}$, in contrast to the $r^{-1}$ dependence for spherical propagation. For cylindrical sources, the curves in the figure are shifted upward with a factor $(r / R)^{1 / 2}$, where $r$ is the detcction distance (depth) and $R$ is the radius of the source.

\section{Conclusions}

In the introduction, we stated that, for applications with tissue, wo had to reconsider tho signal processing of PA detcction. We have scen that the sensitivity of the piezoelectric $\mathrm{PVF}_{2}$ hydrophones is limited primarily by the noise sources of the operational amplifier that is used for preamplification of the sensor signal. There is not much difference between VA and CA, but; for the OpAmps used, the SNR is somewhat larger with CA than with VA. The maximal difference was found for a sensor capacitance of $30 \mathrm{pF}$. For sensors with a small capacitance, VA was preferred because of the higher output signal, reducing the need of further signal amplification. The noise equivalent pressure amplituldes of these hydrophones are lower than those of commercially available necdle hydrophones or than the values reported in litcrature.

The influence of acoustic interference (spatial pressure averaging) on the hydrophone output was demonstrated, and criteria for the dimensions of the disk detector were doveloped. This detector has a large angle of acceptance. The ring detectors have a much moro forward peaked sensitivity and may, thorofore, bo used for on-axis monitoring, especially if a number of concentric rings is used to reduce side lobes.

Because of the broadband characteristics of polymer films and because of the easy handling of these films, $\mathrm{PVF}_{2}$ was used as the sensor material. From the curves for the detectability of $0.4-\mathrm{mm}$ diameter spherical PA sources in tissue with blood-like absorption, for various hydrophones, the following SNR parameters for PA doteclion can be derived. At a depth of $2 \mathrm{~mm}$, typical $\mathrm{SNR}$ values range between 40 and 200 for $532 \mathrm{~nm}$ and between 0.7 and 3 
TABI,E II

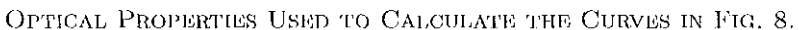

\begin{tabular}{llllll}
\hline Wavelength (nm) & $\mu_{a}\left(\mathrm{~mm}^{-1}\right)$ & $\mu_{s}^{\prime}\left(\mathrm{mm}^{-1}\right)$ & $\mu_{t r}\left(\mathrm{~mm}^{-1}\right)$ & $\mu_{e f f}\left(\mathrm{~mm}^{-1}\right)$ & $l_{t}^{\prime}(\mathrm{mm})$ \\
\hline 532 & 0.1 & 1.5 & 1.6 & 0.69 & 0.63 \\
800 & 0.03 & 0.75 & 0.78 & 0.27 & 1.28 \\
\hline
\end{tabular}

for $800 \mathrm{~nm}$; at a depth of $6 \mathrm{~mm}$, these values range between 0.9 and 4 for $532 \mathrm{~nm}$ and between 0.1 and 0.5 for $800 \mathrm{~nm}$. Those values are for a laser pulse encrgy of $1 \mathrm{~mJ}$. However, because of the much lower absorption of neal infrared light in tissue, a much higher laser pulse encrgy may be applicd, which results in a much higher SNR valıc for this case. We have shown that with a $200-\mu$ m diameter disk, transducer microstructures with blood-like absorption in media such as tissue can be detected up to depths of $6 \mathrm{~mm}$ using 532-nm laser pulses. This transducer is very suitable for application in a matrix sonsor for 3-D PA tissue imaging because of its small lateral dimonsions and its higher SNR compared with commorcially available noedle hydrophones. For PA imaging at depths up to about $5 \mathrm{~mm}$, tho shorter wavelengths are proferred because of the large contrast and the high resolution that can be obtained; for depths larger than about 6 mrr, near infrared light is proferred. Larger depths can be rached with larger sensor diameters and a larger piczoclectric film thickness, both at the cost of resolving power. The radiant fluence attenuation with depth was taken for a worst case (rather high absorption was assumed), and the maximnm detection depth is likely to be larger than indicated by the calculated curves. For the detection of cylindrical sources, the dependence on the depth is reduced. In practice, with the appropriate parameter values, it should be possible to detect sources with a diameter of scveral tenths of a millimeter up to about a $2-\mathrm{cm}$ depth without the use of large focusing transducers. For a spherical source with this diameter, the maximum depth of detcction is about $1.5 \mathrm{~cm}$ under the same conditions. Broad beam irradiation may further increase the maximum detection depth.

\section{RELERENCLS}

[1] A. C. Tam, "Applications of photoaconstic sensing techniques," Rev. Mod. Phys, vol. 58, pp. 381-431, 1986.

[2] S. J. Davies, C. Edwards, G. S. Taylor, and B. S. Palmer, "Lascrgenerated ultrasound: Its properties, mechanisins and multifarious applications," J. Phys. D: Appl. Phys., vol. 26, pp. 329-348, 1993.

[3] C. K. N. Patel and A. C. Tam, "Pulsed optoacoustic spectroscopy of condensed matter," Rev. Modern Phys., vol. 53, pp. $51.7-550,1981$.

[4] D. A. Hutchins, "Mechanisms of pulsed photoacoustic generation," Can. J. I'hys., vol. 64, pp. 1247-1264, 1986.

[5] D. A. Hutchins and A. C. Tarn, "Pulsed photoacoustic materials charactcrization," IEEE Trans. Ultrason., Ferroelect., Frea. Contr., vol. 33, pp. 429-449, 1986.

[6] M. W. Sigrist, "Wascr gencration of acoustic waves in liquids and gascs." J. Appl. Phys. vol. 60, pp. R83 R121, 1986.

[7] C. G. A. Hoclen and F. F. M. de Mul, "A new theoretical approach to photoacoustic signal generation," J. Acoust. Soc Amer., vol. 80, pp. $695 \quad 706,1999$
[8] Q. X. Chen, A. Davies, R. J. Dewhurst, and P. A. Payne, "Photoacoustic probe for intra-arterial imaging and therapy," Elect. Lett., vol. 29, pp. 1632-1633, 1993.

[9] Q. X. Chen, R. J. Dewhurst, P. A. Payne, and B. Wood, "A now lasor-ultrasound transducer for medical applications," Ultrasonics, vol. 32, pp. 309-313, 1994.

[10] P. C. Beard and T. N. Mills, "An optical fibre sonsor for the detection of laser generated ultrasound in arterial tissues," in Proc. SPIL, vol. 2331, pp. 112-122, 1994.

[11] M. Kirschner, G. Paltauf, and H. Schmidi-Kloiber, "Determination of optical properties by measuring laser induced acoustic transients," ir Proc. Biomedical Systems and Technologies, SPIE, vol. 2928, B. Chance, Ed. pp. 28-38, 1996.

[12] S. Lohmann, S. Lohmann, C. Ruff, and C. H. Smitz, "Photoaconstic determination of optical paramoters of biological tissue," in Proc. Lascr-T'issue Interaction and Tissue Optics II SPIS, vol. 2923, H. J. Nlbrecht and G. P. Delacretar, Eds. pp. 2-11, 1996.

[13] A. A. Karabutov, N. B. Podymova, and V. S. Letokhov, "Timeresolved optoacoustic moasurement of absorption of light by inhomogoneous media," Appl. Optics, vol. 34, pp. 1484-1487, 1995.

[14] A. A. Oraevsky, S. L. Jacques, and F. K. Tittel, "Measurement of tissue optical proportios by time-resolved cletuction of laserinduced transient stress," Appl. Optics, vol. 36, pp. 402-415, 1997.

[15] R. O. Escnalicv, A. A. Karabutov, and A. A. Oraevsky, "Sonsitivity of laser opto-acoustic imaging in detection of small docply cmbeddod tumors," IETE J. Select. Topics Quantum Electron. vol. 5, pp. $981988,1999$.

[16] A. ^. Oraevsky, R. O. Psenaliev, S. L. Jacques, S. I. Thomson, and F. K. Tittel, "Lateral and z-axial resolution in laser optoacoustic imaging with ultrasonic transducers," in Proc. Optical Tomography, Photon Migration and Spectroscopy of Tissues, SPIE, B. Chanco and R. Alfano, Uds. vol. 2389, pp. 198-208, 1995.

[17] 12. O. Esenaliev, $\Lambda$. A. Karabutov, F. K. T'ittel, and $\Lambda$. A. Oracvsky, "Laser optoaconstic imaging for breast cancer diagnistics: Limit of detection and comparison with x-ray and ultrasound imaging," in Proc. Optical Tomography and Spectroscopy of Tissue, SPIE, B. Chance and IR. Alfano, Eds. vol. 2979, pp. $71-83,1997$.

[18] C.G.A. Hoclen, F.F.M. do Mul, R. Pongers, and A. Dekker, "Throc-dimensional photoacoustic imaging of blood vossels in tissue," Optics Lett., vol. 23, pp. 648 650, 1998.

[19] C.G.A. Hoolen, R. Pongers, G. Hamhuis, and F.F.M. de Mul, "Photoacoustic blood cell detection and imaging of blood vessels in phantom tissue," in Iroc. Opt. Imag. Techn. Biomonitoring, $S P I E$, II. J. Foth, R. Marchesini, and M. Podbielska, Eds. vol. 3196 , pp. $142-153,1997$.

[20] C.G.A. Hoelen, R. Pongers, A. Dokker, and F.F.M. de Mul, "3Dphotoacoustic imaging of blood vessels," in Advances in Optical Imaging and Photon Migration, vol. 21, J. G. Fuhimoto and M. Patterson, Eds. Washington, DC: Optical Society of America, 1998 , pp. $386-390$.

[21] C.G.A. Hoelen, R.G.M. Kolkman, M. Leffeboor, R. Berendsen, and F.F.M. do Mul, "Photoacoustic tissue scanning (PATS)," in Proc. Optical Timography and Spectroscopy of Tissue III, SPIE, B. Chance, R. Alfano, and B. Tromberg, Fds. vol. 3597, pp. 336$344,1999$.

[22] C. B. Scruby and L. E. Drain, Laser Ultrasonics; Techniques and Applications. A. IIilger, Ed. Bristol, UK, 1990.

[23] C. B. Scruby and K. A. Stacey, "Acoustic emission measuremonts on I'WIR weld material with inserted defects," J. Acoust. Emission, vol. 7, pp. 81. 93, 1988. 
[24] D. R. Bacon, "Characteristics of a PVDF member hydrophono for use in the range 1-100 MH\%" IEEE Trans. Sonics Ultrason., vol. SU-29, pp. $18-25,1982$.

[25] R. J. Dowhurst, C. E. Fdwards, A. 1). W. McKio, and S. B. Palmer, "Comparative study of wideband ultrasonic transducers," Ultrasonics, vol. 25, pp. 315-321, 1987.

[26] P. C. Board, F. Pćronnès, and T'. N. Mills, "Transdıction mochanisms of the Fabry-Perot polymer film sensing concept for wideband ultrasound detection," IEEE Trans. Ultrason., Ferroclcct., Freq. Contr., vol. 46, pp. 1575-1582, 1999.

[27] V. M. Ristic, "Piczoclectric bulk wave transducers," in Principles of Acoustic Devices. New York: J. Wiley \& Sons, 1983, ch. 5 .

[28] G. Gerliczy and R. Bet», "SOLEF PVDF' biaxially oriented piczo- and pyroelectric films for transducers," Sensors Actuators, vol. 12 , pp. 207-223, 1987.

[29] J. Callorame, R. H. Tanerell, and D. T'. Wilson, "Comparison of ceramic and polyner transducers for medical imaging;" in $l E W E$ Proc. Ultrason. Symp., vol. 78CII 1344-ISU, 1978, pp. 117121

[30] G. R. Harris, "Sensilivity considerations for IVDF hydrophones nsing the spot-poled membrane design," IEF $E^{\prime}$ Trans. Sonics Ultrason., vol. SU-29, pp. 370-377, 1982.

[31] P. $\wedge$. Lewin, "Miniature piozoclectric polymer hydrophones in biomedical ultrasonics," Ferroclectrics, vol, 60, pp. 127-139, 1984 .

[32] H. L. W. Chan, A. H. Ramelan, I. I. Guy, and D. C. Price "Piczoelectric copolymer hydrophones for ultrasonic fiold characterization," Rev. Sci. Instrum., vol. 62, pp. 203-207, 1991.

[33] D. G. Shombort, S. W. Smith, and G. II. Harris, "Angular ro sponses of miniature ultrasonic hydrophones," Med. Phys, vol. 9, pp. 484-492, 1982.

[34] P. A. Lowin, "Miniature piczoclectric polymer ultrasonic hydrophono probes," Ultrasonics, vol. 19, pp. $213216,1981$.

[35] D. R. Bacon, "Propertios of a PVDH" hydrophone with $100 \mathrm{MH}$ bandwidth for studying modical, nonlincar and other ficlds," in IEEE Proc. Ultrason. Symp., 1980, pp. 582-585.

[36] G. R. Harris, "Hydrophono measurements in diagnostic ultrasonic ficlds," ITEL Trans, Ultruson., Perroelect., Freq. Contr., vol. 35 , pp. $87 \cdot 101,1988$.

[37] P. A. Lewin and M. H. Schafer, "Wide-band piezoclectric polymer acoustic sources," IEEE 7rans. Ultrason., Fcrroelect., Fren. Contr., vol. 35, pp. 175-184, 1988.

[38] K.-II. Hollwege, Fd. "Numerical data and functional relationships in science and technology," in Landolt-Börnstein New SC rics: Crystal and Solid State Physics. vol. 11, Borlin: Springer, 1979 .
[39] K.-H. Hellwoge, Ed. "Forro- and artiforroelectric substances," in Landolt-Börnstein New Series, Group III: Crystal and Solid State Physics. vol. 3, Berlin: Springer, 1969.

[40] J. W. Waandors, "Piezoelcctric ceranics. Proportios and applications," Philips Components Marketing Communications, Findhoven, The Nelherlands, 1991.

[41] Data shoets on piozoclectric polymer filus, Piezotoch S. A., Franco; AMP Ittd., England; ATOCIJEM Sensors Ltd., Scotland; Solvay S. A., J3elgium.

[42] P. A. Jewin, M. F. Schafer, and IR. C. Chivers, "Factors affecting the choice of preamplification for ultrusonic hydrophone probes," Ultrasound Med. Biol., vol. 13, pp. 141 148, 1987.

[43] J. Davidse, "Ruisarm ontwerpen in de electronica on communicalietechniek", Delft University of Technology, Kluwer 'Technische Bocken B.V,, Joventer, 1988.

[44] C. Tocci, Applied Maple for Enginecrs and Scienlists. Boston, MA: Aztoch House, 1991.

Christoph Hoelen studied applied physics at, the University of Twente, The Nethorlands, and rocoived his Masters dogree in 1993. In 1998, ho received his Ph.D. at the samo university, where he worked in the Applied Optics Group of the Department of Applied L'hysics. The subjoct of his thesis was the photoacoustic characterization of structures in biological tissue with the goal of noninvasivo throedimensional tissue innaging for modical diagnosis. Afterward, he continued this work as PostDoc in this group, now called the Biomedical Optics Group. In 1999, he moved to P'hilips Iighting, whero he currently works as Development Engineor in the Central Development Lamps Department.

Frits de Mul studied applied physics at Technical University, Delft. He received his M.Sc, in 1966 and his Ph.D. degree in 1973 in Radiation Physics. From 1973 to 1976, he taught physics at the secondary school level and, from 1976 to 1981, at the Department; of Applicd Physics at the University of 'T'wente. From 1981 until now, he has boen a member of the Biophysical Technology group and is working in the field of non-invasive biomedical optical diagnostic ticchnology. 